\title{
Short communication: Heat treatment and souring do not affect milk estrone and $17 \beta$-estradiol concentrations
}

\author{
T. Snoj, ${ }^{1}$ M. C. Zuzek, N. Cebulj-Kadunc, and G. Majdic \\ Institute of Preclinical Sciences, Veterinary Faculty, University of Ljubljana, Gerbiceva 60, 1000 Ljubljana, Slovenia
}

\begin{abstract}
The aim of our study was to establish whether heat treatment and souring of milk affect its estrone (E1) and 17ß-estradiol (E2) concentrations. Milk samples were collected from 10 Holstein cows in late pregnancy. Concentrations of E1 and E2 were measured in milk samples that were previously heated to 70 and $95^{\circ} \mathrm{C}$ for 5 min. Additionally, E1 and E2 concentrations were determined in the same milk samples after $2 \mathrm{~d}$ of spontaneous souring at room temperature, and these samples were compared with E1 and E2 levels in raw, unprocessed milk. Concentrations of both hormones were determined by commercial ELISA kits. Concentrations of E1 in unprocessed and processed milk (milk heated to 70 and $95^{\circ} \mathrm{C}$ and soured milk) were (mean $\left.\pm \mathrm{SE}\right) 47.25$ $\pm 4.16,44.84 \pm 3.47,41.00 \pm 4.55$, and $44.92 \pm 3.91$ $\mathrm{pg} / \mathrm{mL}$, respectively. Concentrations of $\mathrm{E} 2$ in the same milk samples were $36.11 \pm 10.01,32.46 \pm 9.88,31.78 \pm$ 9.56 , and $31.43 \pm 8.00 \mathrm{pg} / \mathrm{mL}$, respectively. Concentrations of E1 and E2 in heat-treated milk did not differ significantly from those in unprocessed milk. Similarly, E1 and E2 concentrations in soured milk did not differ significantly from those in unprocessed milk samples. These results indicate that E1 and E2 are stable in milk and that milk processing (heating and souring) does not influence their degradation. Therefore, E1 and E2 concentrations are expected to be similar between commercial full-fat milk and the raw milk from which it was produced.
\end{abstract}

Key words: estrone, $17 \beta$-estradiol, heat-treated milk, soured milk

\section{Short Communication}

Estrogens regulate reproduction, growth, and several other processes within organisms (Davidson and Stabenfeldt, 2013). They are excreted from the body mostly through bile and urine. The presence of estro-

Received May 22, 2017.

Accepted September 9, 2017.

${ }^{1}$ Corresponding author: tomaz.snoj@vf.uni-lj.si gens in milk is a result of their passage through the blood-milk barrier (Schams and Karg, 1986) and, in part, to production of estrogen in mammary gland tissue (Janowski et al., 2002). Low concentrations of estrogens are detected in the milk of non-pregnant cows, whereas concentrations increase during pregnancy and reach peak levels during the third trimester of pregnancy, as expected (Malekinejad et al., 2006; Pape-Zambito et al., 2008). The presence of estrogens in cow milk has prompted discussion about their potential carcinogenic and endocrine-disruptive effects on consumers. Some epidemiological studies have suggested the presence of a correlation between milk consumption and reproductive disorders or the incidence of hormone-related cancers (Ganmaa et al., 2001; Ganmaa and Sato, 2005). However, in a review and meta-analysis by Larsson et al. (2015), no association was found between milk consumption and all causes of mortality. Additionally, as demonstrated by Davoodi et al. (2013), milk consumption decreases the incidence of colorectal, breast, ovarian, and bladder cancers. Similarly, some experiments with humans or animal models showed disruptive effects of milk estrogens (Ganmaa et al., 2006; Maruyama et al., 2010; Zhou et al., 2010), whereas other studies did not detect harmful effects (Li et al., 2005; Furnari et al., 2012; Grgurevic et al., 2016). Thus, there is no consensus about the possible disruptive effects of milk estrogens on human health. Additionally, there are no determined maximal residue limits for estrone (E1) and 17 $\beta$-estradiol (E2) in milk and dairy products. Recommended concentrations of some hormonal compounds for which maximal residue limits have not been established are stated in European Union documents (European Community, 2007); a recommended concentration in this document was provided only for E2 in blood serum and muscle tissue, and milk was not mentioned in the document.

Studies investigating concentrations of milk estrogens report a wide range of levels in milk. Farlow et al. (2012) measured 14.45 and $5.84 \mathrm{pg} / \mathrm{mL}$ of E1 and E2, respectively, in regular whole milk. Pape-Zambito et al. (2008) reported 0.6 and $0.3 \mathrm{pg} / \mathrm{mL}$ of milk E1 and E2, respectively, during the first trimester of pregnancy, 
and concentrations of 27.1 and $5.0 \mathrm{pg} / \mathrm{mL}$, respectively, in the third trimester. Malekinejad et al. (2006) reported 9.2 and $10 \mathrm{pg} / \mathrm{mL}$ of $\mathrm{E} 1$ and $\mathrm{E} 2$ in the first trimester of pregnancy, and these levels increased to 118 and $21 \mathrm{pg} / \mathrm{mL}$, respectively, in the third trimester. Vicini et al. (2008) sampled many commercial milk packages and reported mean concentrations of E2 of $4.97 \mathrm{pg} / \mathrm{mL}$ in conventional whole milk and $6.40 \mathrm{pg} /$ $\mathrm{mL}$ in organic whole milk. Milk estrogen concentrations are also correlated with milk fat content, which is expected because estrogens are lipophilic substances (Pape-Zambito et al., 2010; Farlow et al., 2012). According to Pape-Zambito et al. (2010), pasteurization and homogenization do not affect milk E2 concentration. In addition to the study by Pape-Zambito et al. (2010), which studied only pasteurization, we did not find information in prior studies about whether heat processing at higher temperatures than those used for pasteurization or the souring of milk affected the E1 and E2 concentrations in milk. Therefore, the aim of our study was to establish whether heating to 70 and $95^{\circ} \mathrm{C}$ or the souring of milk would affect E1 and E2 concentrations.

Our study was designed to measure E1 and E2 concentrations in milk samples that were processed in different manners. Milk samples were obtained from 10 pregnant Holstein cows from an organic dairy farm during the last 2 mo of their pregnancy. All milk samples were collected during the morning milking. Four cows were in first lactation, 3 were in second lactation, and 3 were in third lactation. Further information about the animals, their milk yield and milk composition are presented in Table 1. Samples were collected over the course of the entire milking by an in-line sampling device. We collected a 300-mL sample of milk from each cow and stored the sample in a plastic bottle. The bottles were placed in a cooled transport bag and transported to the laboratory within $2 \mathrm{~h}$ after sampling.

Each of the 10 milk samples was divided into 4 parts. One part was analyzed for E1 and E2 concentrations in native milk, one part was heated to $70^{\circ} \mathrm{C}$, one part was

Table 1. Stage of pregnancy in cows $(\mathrm{n}=10)$ and composition of their milk ${ }^{1}$

\begin{tabular}{lcc}
\hline Item & Mean \pm SE & Range \\
\hline Pregnancy (d) & $222 \pm 4.85$ & $202-245$ \\
Daily milk yield (L) & $8.8 \pm 0.37$ & $6.2-10.0$ \\
Fat $(\%)$ & $4.50 \pm 0.25$ & $3.90-6.01$ \\
Proteins $(\%)$ & $3.60 \pm 0.12$ & $3.06-4.29$ \\
Lactose $(\%)$ & $4.44 \pm 0.06$ & $4.03-4.65$ \\
SCC $\left(\times 10^{3}\right.$ cells $\left./ \mathrm{mL}\right)$ & $212 \pm 42.65$ & $55-435$ \\
\hline
\end{tabular}

${ }^{1}$ Data (means $\pm \mathrm{SE}$ ) collected from milk recording performed on the day of milk sampling. heated to $95^{\circ} \mathrm{C}$, and one part was left to sour spontaneously.

In the laboratory, milk samples were mixed thoroughly and $2 \times 1.5 \mathrm{~mL}$ of each sample were transferred to 1.5 -mL polypropylene tubes (Eppendorf, Hamburg, Germany). These samples were intended for determining E1 and E2 levels in raw milk and were stored at $-20^{\circ} \mathrm{C}$ until measurement. Afterward, we divided the remaining milk sample into 3 aliquots of approximately $100 \mathrm{~mL}$ each. First, the aliquots were placed in a water bath (Memmert, Schwabach, Germany) heated to $70^{\circ} \mathrm{C}$. When the milk samples reached $70^{\circ} \mathrm{C}$ (with temperature controlled by a calibrated thermometer), the samples were incubated in the water bath for exactly $5 \mathrm{~min}$. The samples were then removed from the water bath and left to cool to room temperature while mixing on a magnetic stirrer at $200 \mathrm{rpm}$. The same procedure was used for the second aliquots with the water bath heated to $95^{\circ} \mathrm{C}$. After reaching room temperature, $2 \times 1.5 \mathrm{~mL}$ of each sample were transferred to polypropylene tubes (Eppendorf) and stored at $-20^{\circ} \mathrm{C}$ until analysis. The third aliquot was left at room temperature to sour spontaneously. After $2 \mathrm{~d}$, the soured milk was mixed thoroughly with a glass stick. The $\mathrm{pH}$ of the soured milk and fresh milk samples was determined (pH-meter 5735, Iskra, Horjul, Slovenia). Each sample of soured milk was stored as described previously. We determined the milk E1 and E2 concentrations using Estrone ELISA and Estradiol sensitive ELISA kits (both produced by Demeditec Diagnostics, Kiel-Wellsee, Germany). Because these kits are not validated for the detection of E1 and E2 in milk, we previously performed a partial validation of the test. The validation showed that recovery rates were $100 \%$ and $107 \%$ for measuring milk E1 and E2, respectively. Interassay coefficients of variation $(\mathrm{CV})$ were $12.40 \%$ for $\mathrm{E} 1$ and $14.26 \%$ for $\mathrm{E} 2$ measurements. More details on the validation that was performed in our laboratory are described in Grgurevic et al. (2016). The quality of measurements of milk E1 and E2 concentrations in this study was evaluated by intraassay CV, which were $6.72 \%(\mathrm{n}=5)$ and $8.88 \%(\mathrm{n}$ $=5$ ) for E1 and E2, respectively. The ranges of detection for the ELISA kits (6.5 to $500 \mathrm{pg} / \mathrm{mL}$ for E1 and 1.5 to $200 \mathrm{pg} / \mathrm{mL}$ for E2) are appropriate for measuring E1 and E2 in milk because several studies report that E1 and E2 levels are within these detection ranges (Malekinejad et al., 2006; Pape-Zambito et al., 2008, 2010; Farlow et al., 2012; Goyon et al., 2016). Thus, we believe that the method we used was adequate for determining E1 and E2 concentrations in milk.

Statistical analysis of the data was performed using SPSS version 21 (SPSS/IBM Corp., Armonk, NY). The Shapiro-Wilk test was used for the estimation of data distribution. Repeated-measures ANOVA with the 
Bonferroni post hoc test was used to evaluate significant differences between E1 and E2 concentrations in raw and heat-treated milk. The E1 and E2 levels in raw and soured milk were compared by a paired sample $t$-test. Data were considered significant at $P<0.05$. All results are reported as mean $\pm \mathrm{SE}$.

Because the cows were in different lactations, we first checked potential differences in E1 and E2 concentrations between milk samples according to lactation number. We detected no significant differences between milk from cows in first, second, or third lactation (data not shown). This finding was similar to the results of a study by Quist et al. (2008), who reported that, in cows milked twice daily, no differences were found in milk fat content between cows in different lactations. Furthermore, in the current study, neither heat treatment nor souring of the milk affected E1 and E2 concentrations compared with unprocessed milk samples. In our study, E1 concentrations in unprocessed and processed milk (milk heated to 70 and $95^{\circ} \mathrm{C}$ and soured milk) were $47.25 \pm 4.16,44.84 \pm 3.47,41.00 \pm 4.55$, and 44.92 $\pm 3.91 \mathrm{pg} / \mathrm{mL}$, respectively. The E2 concentrations in the same milk samples were $36.11 \pm 10.01,32.46 \pm$ $9.88,31.78 \pm 9.56$, and $31.43 \pm 8.00 \mathrm{pg} / \mathrm{mL}$. Although the concentrations were slightly lower in heated milk samples, the difference was not statistically significant.

Pasteurization in the dairy industry is performed at temperatures between 63 and $100^{\circ} \mathrm{C}$ (The Commission of the European Communities, 2005). We selected 2 temperature points and equal durations of heat exposure to evaluate the influence of temperature on E1 and E2 stability in milk. No significant differences were observed in milk E1 and E2 concentrations between raw milk and milk samples heated to 70 or $95^{\circ} \mathrm{C}$ (Figure 1). Therefore, these results suggest that heat treatment of milk, even at $95^{\circ} \mathrm{C}$ (which is higher than usual pasteurization temperatures), does not affect the chemical structure of E1 or E2 and that their concentrations in the milk were the same as in the raw, unprocessed milk. The presence of estrogens in heat-treated commercial milk has been described several times (Pape-Zambito et al., 2008; Vicini et al., 2008; Farlow et al., 2012). However, those studies did not provide information about estrogen levels in the same milk before heat treatment. Our study was designed to follow E1 and E2 levels in same native and treated milk samples. Because similar concentrations of $\mathrm{E} 1$ and $\mathrm{E} 2$ were measured in unheated (raw) milk and in milk heated to 70 or $95^{\circ} \mathrm{C}$ for $5 \mathrm{~min}$, we believe that any type of pasteurization would not degrade E1 and E2 significantly. Extrapolating the results of our study, E1 and E2 concentrations are expected to be the same in commercial full-fat milk as they are in the raw milk from which the commercial milk was produced. This assertion refers only to full-fat commercial milk because it was previously shown that estrogen concentrations in commercial milk significantly correlate with the milk fat content (PapeZambito et al., 2010; Farlow et al., 2012). Therefore, skimming milk is expected to reduce the concentration of estrogens in many types of commercial milk. Our results were similar to the results of Braekevelt et al. (2011), who studied the fate of estrogens in heated meat samples and reported that E1 and E2 concentrations were stable during heat processing of meat at $100^{\circ} \mathrm{C}$. In the same study, however, they found a decrease during cooking of some other estrogenic compounds with less biological activity (catechol estrogens). Similar to the study by Braekevelt et al. (2011), the results from the current study indicate that E1 and E2 are stable in a complex emulsion, such as milk, which is a suspension and colloid solution. In the present study, the measured E1 and E2 concentrations were higher than those described by Pape Zambito et al. (2008) and Farlow et al. (2012), yet the level of E1 was lower than that reported in a study by Goyon et al. (2016). The relatively high $\mathrm{E} 1$ and E2 concentrations are likely because milk in the present study originated from cows in late pregnancy (Table 1). The cows were at the end of their lactation period with a low daily milk yield and relatively high milk fat content (Table 1). This status could also contribute to the relatively high milk estrogens levels because milk estrogen concentrations depend on milk fat (Pape-Zambito et al., 2010; Macrina et al., 2012). In our study, the milk of cows in late pregnancy was used because it is known that such milk contains the highest amounts of estrogens (Malekinejad et al., 2006; Pape-Zambito et al., 2008). We considered this milk to be the most relevant material to meet the objectives of our study because high E1 and E2 levels should provide observable changes in estrogen concentrations during heat treatment if changes do occur.

Additionally, we compared E1 and E2 concentrations in raw, spontaneously fermented (soured) milk. As shown in Figure 2, E1 and E2 concentrations did not differ significantly between the examined samples. Many dairy products, such as cream and butter, contain estrogens in amounts that correlate with the fat content of the products (Pape-Zambito et al., 2010). However, there are no reports about possible effects of souring on the concentration of estrogens in milk. The results of our study showed that, similar to heat treatment, souring does not affect $\mathrm{E} 1$ and $\mathrm{E} 2$ levels. The mean $\mathrm{pH}$ values of milk and sour milk samples that were used in our study were $6.74 \pm 0.03$ (range: 6.65-6.97) and $4.39 \pm 0.03$ (range: $4.30-4.58$ ), respectively. The $\mathrm{pH}$ values of soured milk were determined according to the methods of Wilkowske (1954), who determined that the $\mathrm{pH}$ of soured milk ranged from 4.4 to 4.5. As suggested 


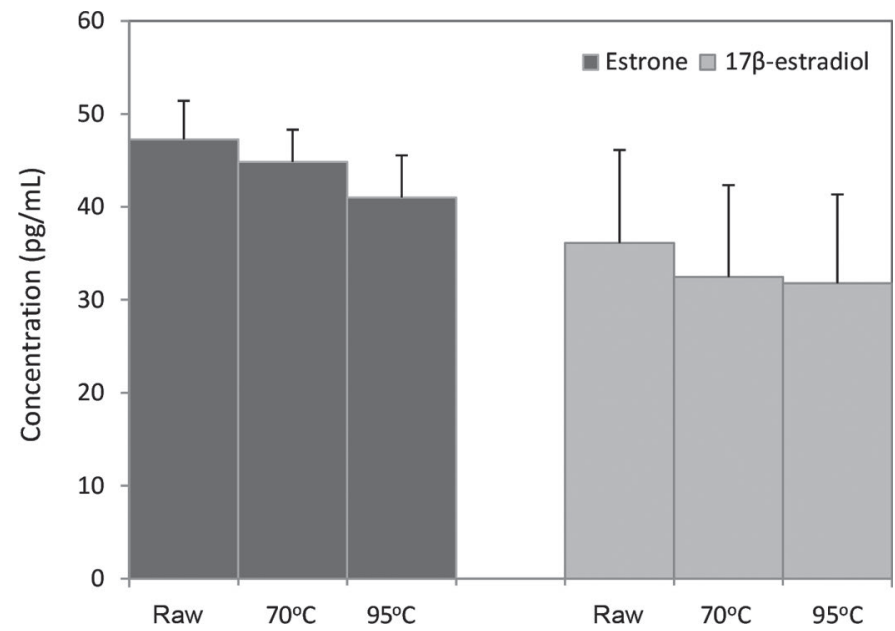

Figure 1. Estrone (E1) and 17ß-estradiol (E2) concentrations (means $\pm \mathrm{SE} ; \mathrm{pg} / \mathrm{mL})$ in samples of raw milk $(\mathrm{n}=10)$ and in the same milk samples that were heated to $70^{\circ} \mathrm{C}(\mathrm{n}=10)$ or $95^{\circ} \mathrm{C}(\mathrm{n}=$ 10) before measurement of hormones. Raw milk was not subjected to heating procedures. Estrone and 17 $\beta$-estradiol concentrations in raw and heat-treated milk did not differ significantly $(P>0.05)$.

from the results of our study, E1 and E2 do not degrade in a $\mathrm{pH}$ range of 4.30 to 4.58 .

Although E1 and E2 do not degrade during heat treatment or souring of milk, these estrogens in processed milk most likely do not pose a risk to human health because it is estimated that no physiological effects occur when the daily consumption of exogenous estrogens is less than $1 \%$ of the endogenous quantities produced by the segment of the population with the lowest daily production (US DHHS-FDA, 2016). As discussed by Macrina et al. (2012), prepubertal girls represent this segment of the population, with minimal estrogen (E1

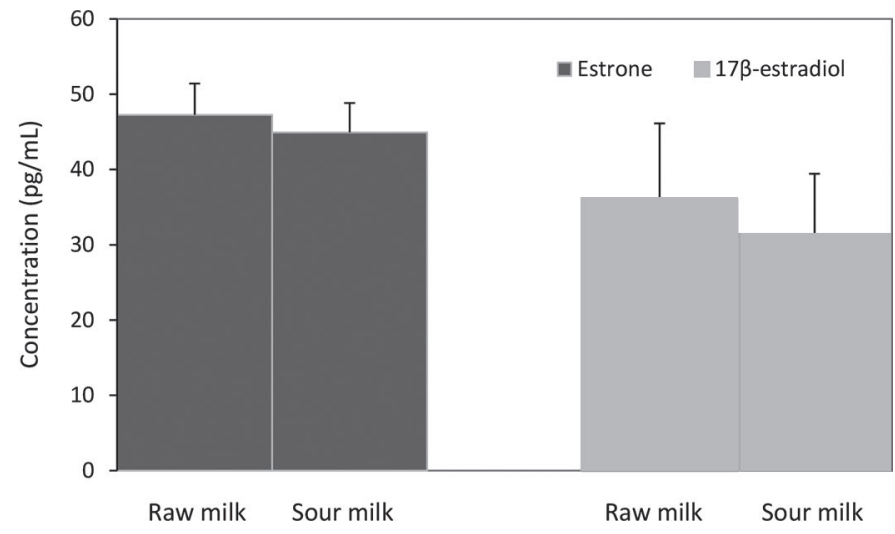

Figure 2. Estrone (E1) and 17ß-estradiol (E2) concentrations (means $\pm \mathrm{SE} ; \mathrm{pg} / \mathrm{mL})$ in samples of raw milk $(\mathrm{n}=10)$ and in milk samples that spontaneously soured $(\mathrm{n}=10)$. The mean $\mathrm{pH}$ values of raw and sour milk were $6.74 \pm 0.03$ and $4.39 \pm 0.03$, respectively. Estrone and $17 \beta$-estradiol concentrations in raw and soured milk did not differ significantly $(P>0.05)$.
+ E2) production $(54,000 \mathrm{ng} / \mathrm{d})$. The combined measured quantity of E1 and E2 in $1 \mathrm{~L}$ of milk used in our study was $83.36 \mathrm{ng}$. This value represents $0.15 \%$ of the daily production of E1 + E2 in prepubertal girls.

In conclusion, the results of our study show that the heat treatment of bovine milk does not influence $\mathrm{E} 1$ and E2 concentrations. Concentrations of E1 and E2 in milk samples heated to 70 and $95^{\circ} \mathrm{C}$ were not significantly different from the respective concentrations in the same samples of milk before processing. Similarly, E1 and E2 concentrations in soured milk were not significantly different from those in raw, unprocessed milk. Therefore, our results suggest that E1 and E2 concentrations are expected to be similar in the commercial full-fat milk and in the raw milk from which the commercial milk was produced.

\section{ACKNOWLEDGMENTS}

This work was financially supported by The Slovenian Research Agency (grant number P4-0053). We thank Katarina Babnik and Boštjan Drolc (Institute of Preclinical Sciences, Veterinary Faculty, University of Ljubljana, Ljubljana. Slovenia) for their technical assistance. The text was edited by American Journal Experts (Durham, NC).

\section{REFERENCES}

Braekevelt, E., B. P. Lau, B. Tague, S. Popovic, and S. A. Tittlemier. 2011. Effect of cooking on concentrations of $\beta$-estradiol and metabolites in model matrices and beef. J. Agric. Food Chem. 59:915-920.

The Commission of the European Communities. 2005. Commission Regulation (EC) NO 2074/2005 of 5 December 2005 laying down implementing measures for certain products under Regulation (EC) No 853/2004 of the European Parliament and the Council and for the organisation of official controls under regulation (EC) No 854/2004 of the European Parliament and the Council and Regulation (EC) No 882/2004 of the Europena Parliament and the Council, derogating from Regulation (EC) No 852/2004 of the European Parliament and the Council and amending Regulations (EC) No 853/2004 and (EC) No 854/2004. (2005). Off. J. Eur. Union L 338:27-59.

Davidson, A. P., and G. H. Stabenfeldt. 2013. Reproduction and lactation. Pages 408-459 in Cunningham's Textbook of Veterinary Physiology. 5th ed. B. G. Klein, ed. Elsevier Saunders, St. Louis, MO.

Davoodi, H., S. Esmaeili, and A. M. Mortazavian. 2013. Effects of milk and milk products consumption on cancer: A review. Comp. Rev. Food Sci. Food Saf. 12:249-264.

European Community. 2007. CRL guidance paper (7 December 2007). CRLs view on state of the art analytical methods for national residue control plans. Accessed Sep. 6, 2017. http://www.rivm.nl/ bibliotheek/digitaaldepot/crlguidance2007.pdf.

Farlow, D. W., X. Xu, and T. D. Veenstra. 2012. Comparison of estrone and $17 \beta$-estradiol levels in commercial goat and cow milk. J. Dairy Sci. 95:1699-1708.

Furnari, C., D. Maroun, S. Gyawali, B. W. Snyder, and A. M. Davis 2012. Lack of biologically active estrogens in commercial cow milk. J. Dairy Sci. 95:9-14. 
Ganmaa, D., and A. Sato. 2005. The possible role of female sex hormones in milk from pregnant cows in the development of breast, ovarian and corpus uteri cancers. Med. Hypotheses 65:1028-1037.

Ganmaa, D., H. Tezuka, D. Enkhmaa, K. Hoshi, and A. Sato. 2006. Commercial cows' milk has uterotrophic activity on the uteri of young ovariectomized rats and immature rats. Int. J. Cancer 118:2363-2365.

Ganmaa, D., P. Y. Wang, L. Q. Qin, K. Hoshi, and A. Sato. 2001. Is milk responsible for male reproductive disorders? Med. Hypotheses 57:510-514.

Goyon, A., C. Z. Cai, K. Kraehenbuehel, C. Hartmann, B. Shao, and P. Molttier. 2016. Determination of steroid hormones in bovine milk by LC-MS/MS and their levels in Swiss Holstein cow milk. Food Addit. Contam. A Chem. Anal. Control Expo. Risk Assess. 33:804-816.

Grgurevic, N., J. Koracin, G. Majdic, and T. Snoj. 2016. Effect of dietary estrogens from bovine milk on blood hormone levels and reproductive organs in mice. J. Dairy Sci. 99:6005-6013.

Janowski, T., S. Zdunzyk, J. Malecki-Tepicht, W. Baranski, and A. Ras. 2002. Mammary secretion of oestrogens in the cow. Domest. Anim. Endocrinol. 23:125-137.

Larsson, S. C., A. Crippa, N. Orsini, A. Wolk, and K. Michaëlsson. 2015. Milk consumption and mortality from all causes, cardiovascular disease, and cancer: A systematic review and meta-analysis. Nutrients 7:7749-7763.

Li, X. M., D. Ganmaa, L. Q. Qin, and A. Sato. 2005. Testing potential effect of environmental endocrine disruptors in cow milk on reproductive index in female rats. Biomed. Environ. Sci. 18:307-313.

Macrina, A. L., T. L. Ott, R. F. Roberts, and R. S. Kensinger. 2012. Estrone and estrone sulfate concentrations in milk and milk fractions. J. Acad. Nutr. Diet. 112:1088-1093.

Malekinejad, H., P. Scherpenisse, and A. A. Bergwerff. 2006. Naturally occurring estrogens in processed milk and in raw milk (from gestated cows). J. Agric. Food Chem. 54:9785-9791.
Maruyama, K., T. Oshima, and K. Olyama. 2010. Exposure to exogenous estrogen through intake of commercial milk produced from pregnant cows. Pediatr. Int. 52:33-38.

Pape-Zambito, D. A., A. L. Magliaro, and R. S. Kensinger. 2008. $17 \beta$-estradiol and estrone concentrations in plasma and milk during bovine pregnancy. J. Dairy Sci. 91:127-135.

Pape-Zambito, D. A., R. F. Roberts, and R. S. Kensinger. 2010. Estrone and $17 \beta$-estradiol concentrations in pasteurized-homogenized milk and commercial dairy products. J. Dairy Sci. 93:2533-2540.

Quist, M. A., S. J. LeBlanc, K. J. Hand, D. Lazenby, F. Miglior, and D. F. Kelton. 2008. Milking-to-milking variability for milk yield, fat and protein percentage and somatic cell count. J. Dairy Sci. 91:3412-3423.

Schams, D., and H. Karg. 1986. Hormones in milk. Ann. N. Y. Acad. Sci. $464: 75-86$.

US DHHS-FDA (Department of Health and Human ServicesFood and Drug Administration). 2016. Guidance for industry. General principles for evaluating the human food safety of new animal drugs used in food-producing animals. Accessed Sep. 6, 2017. https://www.fda.gov/downloads/AnimalVeterinary/ GuidanceComplianceEnforcement/GuidanceforIndustry/ UCM052180.pdf.

Vicini, J., T. Etherton, P. Kris-Etherton, J. Ballam, S. Denham, R. Staub, D. Goldstein, R. Cady, M. McGrath, and M. Lucy. 2008. Survey of retail milk composition as affected by label claims regarding farm-manegement practices. J. Am. Diet. Assoc. 108:1198 1203.

Wilkowske, H. H. 1954. Relationship between titratable acidity and $\mathrm{pH}$ during lactic acid fermentation in reconstituted nonfat milk. J. Dairy Sci. 37:22-29.

Zhou, H., L. Q. Qin, D. F. Ma, Y. Wang, and P. Y. Wang. 2010. Uterotrophic effects of cow milk in immature ovariectomized SpragueDawley rats. Environ. Health Prev. Med. 15:162-168. 